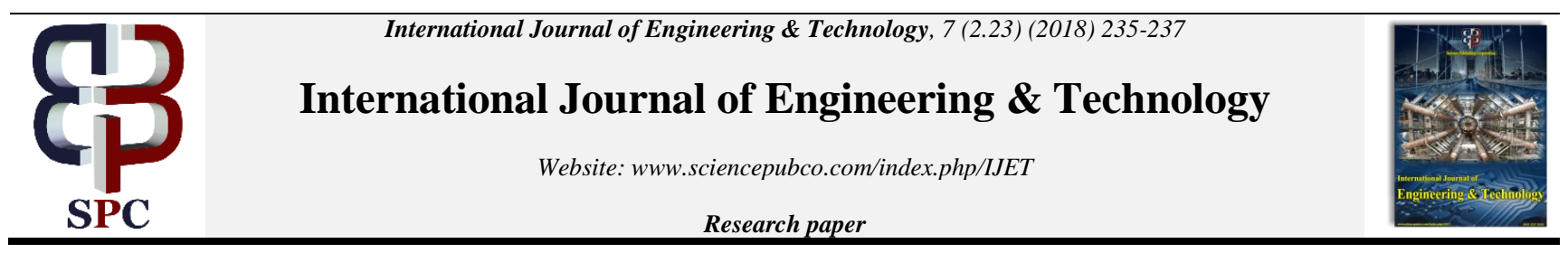

\title{
Stability Analysis of Isolated Hybrid Microgrid for Village Electrification
}

\author{
Kuldip Singh $^{1 *}$, Dr. M. Narendra Kumar ${ }^{2}$, Dr. Satyasis Mishra ${ }^{3}$ \\ ${ }^{I}$ Research Scholar Centurion University, Bhubanesware, Odisha, India \\ ${ }^{2}$ Principal \& Professor, St,Peter's Engineering College, Hyderabad,Telangana,India \\ ${ }^{3}$ Professor, Centurion University, Bhubanesware, Odisha, India \\ *Corresponding author E-mail: ksmann3@gmail.com
}

\begin{abstract}
The village electrification is the main concern for government of India. The isolated Hybrid Microgrid with renewable energy sources has been growing rapidly for village electrification and it is going to play vital role for $100 \%$ electrification in rural area by 2020 . For planning and designing of isolated hybrid microgrid the power system stability is major parameter and its main concern due to instability in load demand as well as in generation from renewable energy sources. For renewable energy sources, the controlling of frequency and voltage deviation is a great challenge. This paper is carry out the stability analysis for PV-Biomass based isolated hybrid microgrid on different load and generation conditions and carry out the effect on frequency stability
\end{abstract}

Keywords: Isolated Hybrid Microgrid; Stability; Load Demand; Generation; Renewable Sources; Frequency.

\section{Introduction}

The isolated Hybrid Microgrid has been growing rapidly for village electrification across the world as well as in India, due to several potential and economic advantages. As conventional power sources are increasing the environmental pollution and more transmission losses, the renewable energy sources are more suitable resource for village electrification as clean energy source [1]. The government of India introduce many schemes for village electrification under rural electrification program grid connectivity and OFF grid mode with renewable energy sources. As traditional or central power generation have long transmission line to the load centre, which may not economical and suitable for village electrification due to high power demand and electric losses in transmission system. The distribution generation with renewable energy sources near to load centre is more economical solution for rural electrification [2][3] For designing and planning of distribution generation system the stability and reliability is main concern for electric system due to instability of load demand and instability in generation from renewable energy sources, which may cause the voltage and frequency stability problem in isolated hybrid microgrid. In this study, we consider the isolated hybrid microgrid with solar PV plant and DG generation with Bio-mass fuel along with local distribution system for village electrification. As load demand and generation from solar PV plant are not constant w.r.t time, sudden voltage and frequency instability is occurring, which may directly be affecting to the operation of DG as well as operation of solar power plant. In recent years, many studies are carry out on modelling, operation and controlling of isolated hybrid microgrid based on simulation approach. For practical isolated hybrid microgrid with local distribution the system stability is major and important concern [4]. This paper carries out the real time study of frequency stability problem in isolated hybrid microgrid with domestic and agricultural load [5]. The main sources of power generation are PV and DG. This paper is structured as follows: In Section 2, the modelling of isolated hybrid microgrid, section 3 , stability of isolated microgrid, section 4 case study and results and finally conclusion in section 5

\section{Proposed System Model for isolated Hy- brid Microgrid}

The study is carry out by two renewable energy sources one is solar PV power plant and second is DG set operating by bio mass and both sources are synchronizing with load through common bus bar for village electrification. The basic architecture of isolated hybrid microgrid is shown in Figure-1.

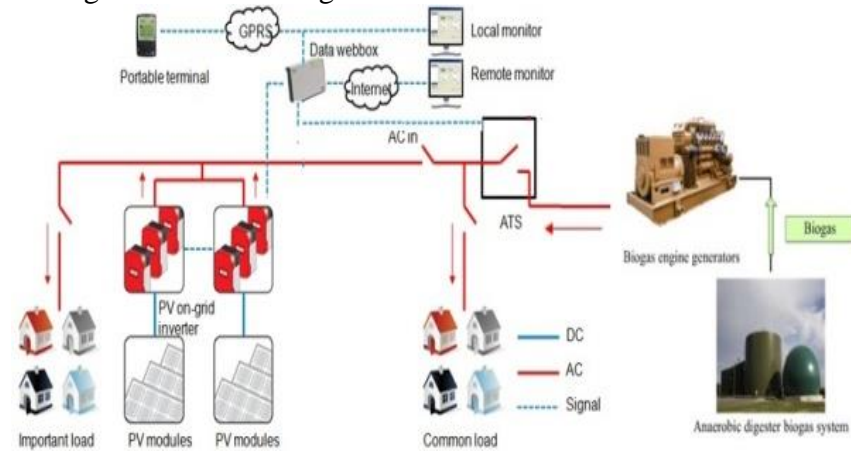

Figure-1 Basic architecture of hybrid isolated microgrid.

Here $P_{D}=$ Total Power Demand

$\mathrm{PPV}=$ Total Power generation from solar power plant

$\mathrm{P}_{\mathrm{DG}}=$ Total Power generation from Bio mass DG set

$\mathbf{P}_{\mathrm{D}}=\mathbf{P}_{\mathrm{PV}}+\mathbf{P}_{\mathrm{DG}}$

a.) PV Plant: The generation of solar power plant is directly or indirectly depending on geographical and climate conditions of the plant location. The major component of solar PV plant are PV 
modules for converting sunlight into electrical energy and grid inverter for converting $\mathrm{DC}$ to $\mathrm{AC}$.

b.) Bio-Mass DG: The Bio-mass based DG system consisting of engine and generator. The engine acts as a prime mover consumes the energy from Bio mass and produce the mechanical energy. The synchronous generator connected to engine for converting mechanical energy into electrical energy. Whenever, sudden power demand is increasing on solar power plant, the DG is compensating the deficit power because solar power plant and DG are synchronizing to common load Bus Bar system [1].

The Transfer function of DG is

$\mathrm{T}_{\mathrm{DG}}(\mathrm{s})=\frac{K_{D G}}{1+t_{D G(s)}}$

Where $\mathrm{K}_{\mathrm{DG}}=$ Gain and $\mathrm{t}_{\mathrm{DG}}=$ Time Constant

\section{Stability of Isolated Hybrid Microgrid}

The stability of a system is referred to the ability of a system to return back to its steady state after disturbance [6]. The stability of isolated hybrid microgrid has been and continues to be of major concern in electrical distribution system. In steady state, solar PV plant and DG have synchronous operation to fulfil the load demand. The stability of isolated hybrid microgrid is determines, whether the generation system can settle down to a new or original steady state after the transients disappear. The stability of distribution generation system is depending upon the loading and sudden changes in load, which can bring onset of instability. The stability of isolated microgrid is an integral property of distribution generation system, which future divided into two parts.

a) Steady state stability: A distribution generation system is steady state stable for a particular steady state operating condition after small disturbance, which is identical or close to the pre-disturbance operating condition. It is function only of the operating condition.

b) Transient Stability: A distribution generation system is transiently stable for a particular steady state operation after large disturbance or sequence of disturbance it, following that it reaches an acceptable steady state operating condition. It is function of operating condition and the disturbance.

As mentioned in section II, load sharing is done by synchronous of solar PV plant and Bio- mass based DG set, the sources are synchronized with common bus bar at same frequency, voltage and phase sequence. The power system stability in isolated hybrid microgrid as ability of the system return to steady state without losing synchronism between solar PV plant and DG set as well as with load [6].

a) Stable state: The isolated hybrid microgrid have stable operation by synchronous of solar PV plant with DG set to fulfil the load demand. The PV plant is operating with reference frequency and voltage of DG set. Under normal operating condition are as follow:

$\boldsymbol{P}_{\boldsymbol{D}}=\boldsymbol{P}_{\boldsymbol{P V}}+\boldsymbol{P}_{\boldsymbol{G}}$

In this case the $P_{D}>P_{P V}$ and complete load demand is sharing by PV plant and DG and no excess power is following from $\mathrm{PV}$ to DG. The PV plant is operating on reference frequency and voltage under normal condition.

$\boldsymbol{F}_{\text {ref }}=\boldsymbol{F}_{G}=\boldsymbol{F}_{P V}$

$V_{\text {ref }}=V_{G}=V_{P V}$

Speed of DG set $=\mathbf{N s}$

Here $P_{D}$ is load demand, $P_{P V}$ is Power generating from solar power plant, $P_{G}$ is Power sharing by Bio-mass based DG set, $\mathrm{F}$ is frequency, $\mathrm{V}$ is voltage and Ns is synchronous speed for DG set.

b) Transient Stability State: In transient stability state the isolated hybrid microgrid have disturbance in solar power generation due to sudden change in frequency stability. Due to frequency change the inverter are not operating under steady state condition. The frequency instability is occurring under following conditions:

$$
\text { Here } \boldsymbol{P}_{\boldsymbol{D}}<\boldsymbol{P}_{\boldsymbol{P V}}
$$$$
\boldsymbol{P}_{G}=\boldsymbol{P}_{P V}+\boldsymbol{P}_{D}
$$

From above equation (7), the reverse power or excess power will follow to DG set, which is main cause for frequency increase under following condition.

In stabile system DG exerts a torque in the direction to the mechanical torque, which retards the motion caused by the mechanical torque (Tm ) and this toque is called electromagnet toque Te. When a DG set is running on synchronous speed (Ns) the is no angular acceleration and

\section{$\mathbf{T m}=\mathbf{T e}$}

When sudden load is decreasing and expressing the equation (6) condition the DG set is experience the positive angular acceleration torque (Ta) in the same direction of applied mechanical toque and increasing the speed of DG set above synchronous speed (Ns).

$\mathbf{T a}=\mathbf{T m}-\mathbf{T e}$

The rate of change of frequency $\left(\frac{d f}{d t}\right)$ is

$\frac{d f}{d t}=\frac{T_{a} f_{o}}{2 H}$

Here $f_{o}$ is base frequency $(50 \mathrm{~Hz})$ and $\mathrm{H}$ is system inertia constant Or

$F=\frac{P \times N}{120}$

Here $\mathrm{F}$ is frequency is number of poles and $\mathrm{N}$ is speed in RPM.

\section{Results and Analysis}

In isolated hybrid microgrid has small capacity, so it need to set aside enough spare generation capacity to compensate for sudden load demand. In this case study, we are using grid inverter, which are operating with reference frequency and voltage from bio-mass based DG set as discussion in section III. The load is sharing on solar PV plant(75kWp) and DG set(125kVA) through common bus bar. The study is carry out on different generation condition as shown in Table-1 for analysis for frequency instability and speed of DG set at minimum load demand due excess generation from solar power plant.

\begin{tabular}{|c|c|c|c|c|c|}
\hline S.No & $\begin{array}{l}\text { Load } \\
\text { Cur- } \\
\text { rent } \\
\left(I_{L}\right) \\
\text { Amp }\end{array}$ & $\begin{array}{l}\text { Gener- } \\
\text { ation } \\
\text { current } \\
\text { from } \\
\text { PV } \\
\left(I_{P V}\right) \\
\text { Amp }\end{array}$ & $\begin{array}{l}\text { Gener- } \\
\text { ation } \\
\text { current } \\
\text { from } \\
\text { DG }\left(I_{G}\right. \\
) \text { Amp }\end{array}$ & $\begin{array}{l}\text { Fre- } \\
\text { quency } \\
(\mathrm{Hz})\end{array}$ & $\begin{array}{l}\text { Speed of } \\
\text { DG set N } \\
(\mathrm{RPM})\end{array}$ \\
\hline 1 & 55.4 & 0 & 55.4 & 48.9 & 1483 \\
\hline 2 & $\begin{array}{r}47.9 \\
8 \\
\end{array}$ & 22 & 25.98 & 49.8 & 1472 \\
\hline 3 & 50.1 & 90.1 & -40 & 51.59 & 1507 \\
\hline 4 & 50.7 & 107.1 & -56.4 & 51.59 & 1534 \\
\hline 5 & 49.1 & 120.6 & -71.5 & 51.62 & 1566 \\
\hline 6 & 60.4 & 0 & 60.4 & 48.9 & 1483 \\
\hline 7 & $\begin{array}{r}54.9 \\
8 \\
\end{array}$ & 25 & 29.98 & 49.8 & 1472 \\
\hline 8 & 49.1 & 87.1 & -38 & 51.59 & 1507 \\
\hline 9 & 55.7 & 107.1 & -51.4 & 51.59 & 1534 \\
\hline 10 & 51.1 & 120.6 & -69.5 & 51.62 & 1566 \\
\hline
\end{tabular}


As data is given in above table the as generation of solar power plant is increasing the reverse power is flowing in the DG set, due to more reverse power flow the positive accelerating torque is acting in same direction of mechanical torque, which is increasing the speed above the synchronization speed and increasing the frequency. When frequency is increasing above the base frequency the inverter is tripping and stopping the operation of solar power plant Increasing in speed is casing the frequency instability problem in isolated hybrid microgrid. The Figure- 2 is shown the relation between solar power plant generation, frequency and speed of the generator, Figure-3 is shown the Speed Vs Frequency and Figure-4 Solar Vs Frequency.

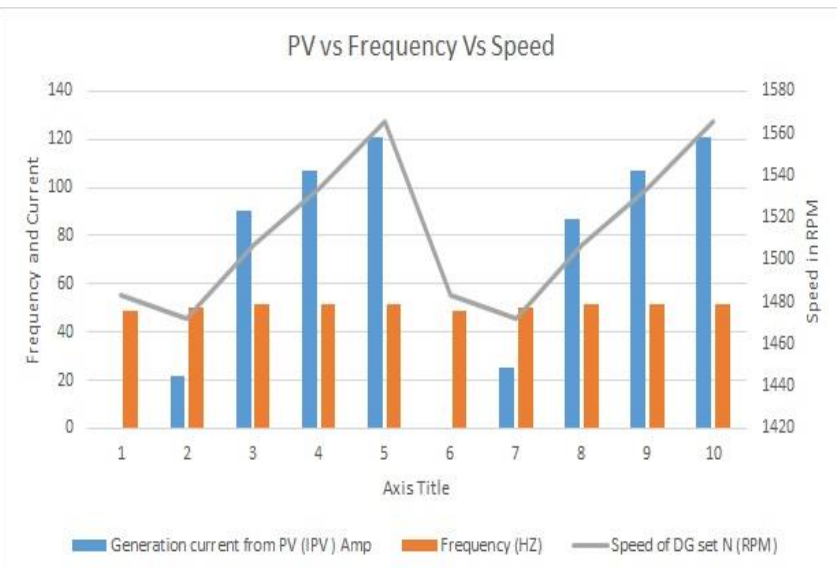

Figure-2 PV Generation Vs Frequency and Speed of DG set

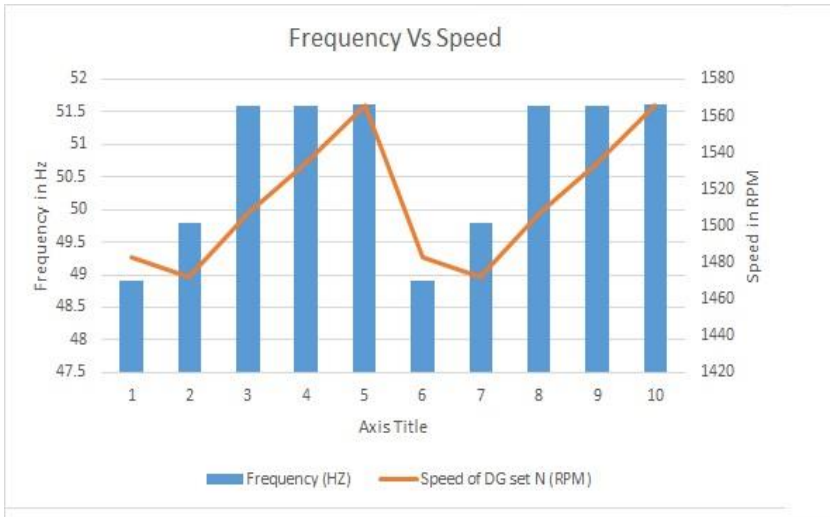

Figure- 3 Frequency Vs Speed

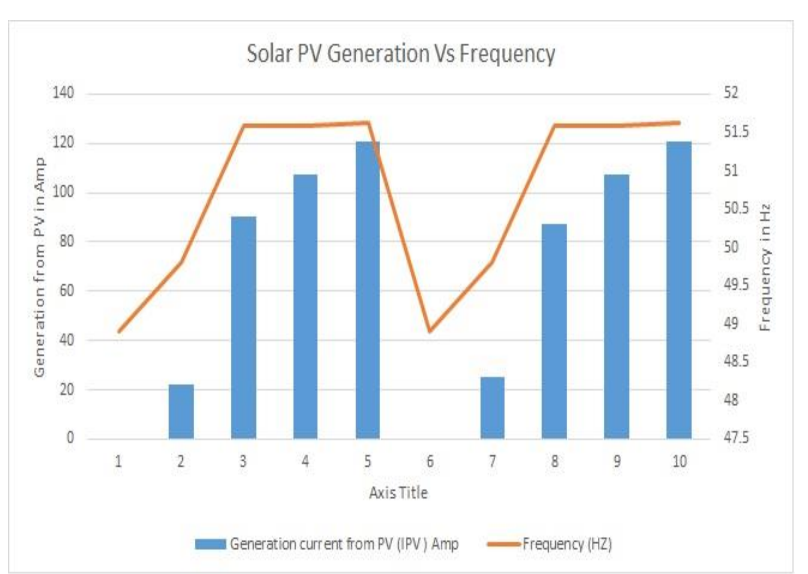

Figure-4 PV Gen Vs Frequency

\section{Conclusion}

The study is carryout on solar power PV plant and DG set based on Bio-mass connected to load in isolated hybrid mode for sharing the load through common bus bar. The study analyses on different solar PV plant generation and the effect of excess or reverse power flow in DG set. When load is less than solar power plant the reverse power is flowing in DG set, which is main cause for positive acceleration torque, which is increasing the speed the of DG set above synchronous speed. The excess speed of DG set is causing for frequency instability and effecting the generation of solar power plant.

\section{References}

[1] A.Jeya Veronica, Dr.N.Senthil Kumar, “Internal Model Based Load Frequency controller Design for Hybrid Microgrid system”, Energy Procedia 117( 2017) pp 1032-1039

[2] Kuldip Singh , M. Narendra Kumar, Satyasis Mishra, "A Review On Village Electrification Challenges \& Solution In India" VOLUME :04 Issue 04 Paper id-IJIERM-IV- IV-1357, August 2017

[3] Kuldip Singh , Swetalina Bhuyan,M. Narendra Kumar, Satyasis Mishra, "Analysis of Voltage Stability in Radial Distribution System for Hybrid Microgrid", Advances in Smart Grid and Renewable Energy, Lecture Notes in Electrical Engineering 435 , (2017) pp49-55

[4] Chen Rouyi,Chen Jianbin, Lei Jinyong, Fu Chao, Wang Ke, Duan Weiguo, Dong Xuzhu, CAI Guangulin, " System stability and its influencing factors analysis of the isolated wind-solar-diesel-battery hybrid microgrid", 2012 china international conference on electrical distribution (CICED 2012) pp 1-4

[5] Mazin T.Muhssin,L.M.Cipcigan, Zeyad Assi Obaid, " Small Microgrid stability and performance analysis in isolated island", Power Engineering Conference (UPEC), 2015 50th International Universities, 03 December 2015 pp 1-6

[6] Md saleh Ebn Sharif,Md Monower Zahid khan,Md Moniruzzaman, Anamika Bose, "Design, simulation and stability analysis of windPV-Diesel hybrid power system using ETAP", American Journal of modern Energy 2017,3(6) pp 121-130 